\title{
Ovarian Dermoid Cyst with Corticotropin Secreting Adenoma
}

National Cancer Institute

\section{Source}

National Cancer Institute. Ovarian Dermoid Cyst with Corticotropin Secreting Adenoma. NCl Thesaurus. Code C40007.

A corticotropin secreting adenoma that has developed in an ovarian dermoid cyst. It may present with Cushing syndrome. The clinical course is benign. 